Vol. 7, No. 2.

ISSN: 1473-8376

www.heacademy.ac.uk/johlste

ACADEMIC PAPER

\title{
An investigation into the tourism and hospitality scholarly activity currently being undertaken in Irish higher education institutions
}

\author{
Noëlle O'Connor (noelle.oconnor@lit.ie) \\ Department of Humanities, School of Business and Humanities, \\ Limerick Institute of Technology, Moylish Park, Limerick, Ireland
}

Tom Baum (t.g.baum@strath.ac.uk)

Department of Hospitality and Tourism Management, University of Strathclyde, 16 Richmond Street, Glasgow G1 1XQ, Scotland

DOI:10.3794/johlste.72.158

(c)Journal of Hospitality, Leisure, Sport and Tourism Education

\begin{abstract}
The purpose of this article is to describe the tourism and hospitality scholarly activity currently taking place in Irish higher education (HE) institutions. A number of approaches to tourism and hospitality research are identified in the literature. In order to understand the policy and practice within the Irish HE sector, qualitative research was conducted through a survey of tourism and hospitality academics and researchers within Irish HE institutions. The findings suggest that tourism and hospitality scholarly activity in Ireland is being carried out in many ways, including through joint research projects between Irish HE institutions and industry. This is a positive step towards achieving research and industry harmony. The development of stand-alone research centres within these institutions can also promote and attract funding for tourism and hospitality research activities.
\end{abstract}

Keywords: Research; Academic; Scholarly activity; Tourism; Hospitality; Ireland

\section{Introduction}

This paper investigates the tourism and hospitality scholarly activity currently being undertaken within tourism and hospitality in Irish HE institutions. The main aims of the research are to assess the linkages between education and research and to identify research issues in relation to tourism and hospitality scholarly activity within these institutions, to facilitate validating theory and to provide advice for tourism and hospitality education decision-makers. This paper proposes changes to the Irish interpretation of the term

Noëlle O'Connor is senior lecturer in tourism and hospitality studies at the Limerick Institute of Technology. She was previously acting head of the Department of Languages, Tourism and Hospitality at the Waterford Institute of Technology and she has lectured for many years at the Dublin Institute of Technology. Noëlle was recently chair of the editorial board for Tourism and Hospitality Research in Ireland.

Tom Baum is professor of international tourism and hospitality management at the University of Strathclyde where, until 2004, he was head. Tom has a BA and MA from the University of Wales and a PhD from Strathclyde. He is a specialist in human resource management, education and training within the international tourism and hospitality sector and has published seven books and over 100 academic papers in this and related areas of tourism and hospitality. 
'research' by involving the term 'scholarly activity' and recommends a suitable course of action, one which demonstrates the scholarly activity taking place.

\section{Brief review of tourism research approaches}

Research involves a diverse blending of an enormous range of skills and activities. To be a good social researcher, you have to be able to work well with a wide range of people, understand the specific methods used to conduct research, understand the subject that you are studying and be able to convince someone to give you the funds to study it, stay on track and on schedule, and to speak and write persuasively (Trochim, 2008). Brown (1980) advocates that the aim of tourism research is to supply data that will help tourism managers when making decisions. Tourism research is an exploratory process that can be differentiated from other forms of exploration by three distinctive requirements: objectivity, reproducibility and systemisation.

According to Jennings (2001), research is an important tool for the tourism industry both nationally and internationally. It provides information for planning and management at the local, regional, national and international levels and offers an insight into the expectations, impacts, motivations, needs and levels of satisfaction of tourists. It highlights the educational needs of commercial operators and service providers and generates temporal views of the past, present and future (Jennings).

Jennings (2001) also maintains that the call for such research is essential owing to tourism's strong growth in the global economy. It could ensure that planning for service provision would be effective and forward-directed rather than reactive to past trends. The enhancement of information technology is also influencing the conduct of tourism research. Information and communications technology (ICT) provides another medium for accessing research participants via online research technologies and methods of conducting research. On the whole, tourism research needs to move to the stage of being interdisciplinary and also towards being a discipline in its own right. Ultimately, it should value qualitative as well as quantitative research methodologies in developing the tourism phenomenon even further (Jennings).

Elsworth, Yoon, and Bai (1999) contend that for tourism research to receive the much needed attention and, as a result, funding from the public and private sectors, the significant research being carried out by tourism researchers needs to be identified. Such areas of research should be distinguished so that the research can focus on particular themes. As additional research in other areas is completed, the necessity for existing tourism journals to specialise in particular types of publications may arise. Academics who contribute to tourism research should review these publications and identify areas of interest with the intention of strengthening the body of literature in tourism research (Elsworth et al.).

Scholarly activity is creative work that is peer reviewed and publicly disseminated (Virginia Polytechnic Institute and State University, 2008). Boyer (1990) suggested four types of scholarship: the scholarship of discovery (discovering new knowledge); the scholarship of integration (connecting information and approaches across disciplines); the scholarship of application (applying knowledge to 'real-life' problems); and the scholarship of teaching (better understanding and creating effective teaching-learning processes) (Boyer). These types have generated a great deal of interest and debate about scholarship. Consequently, it has become evident that a wider range of scholarly work should be accepted over and above traditional research (Roberts, 2006). The term 'scholarly activity' aligns with institutional aims more than a traditional research-as-publication approach.

\section{Research design and methodology}

\section{Introduction}

The main aim of the research was to examine tourism and hospitality scholarly activity within Irish HE institutions and to provide advice for tourism and hospitality education decision- 
makers and researchers. To facilitate developing a comprehensive understanding of the topic under discussion, various methods were measured and used in conjunction with each other, including surveys (Beeton, 2000). Cooper and Emory (1995) argue that it is suitable to use secondary data, as they serve a number of purposes: they give definite reference on points to examine from other findings; they can supply information that can add to the current study; and they can assist in identifying what further research is needed. To support this a descriptive survey was chosen, and secondary data forms the basis of the brief review of tourism research approaches. In preparing the survey, both the research questions and target respondents were considered.

\section{The survey}

Target respondents were employed within the Irish HE sector, either through an institute of technology (IoT), a university or a private college. In the Irish context, an loT provides vocational and technical education and training for the region served by the college (Government of Ireland, 2006). A university is a HE institution committed to teaching and research in the major disciplines (Higher Education Authority, 2008) and a private college is a non state-aided HE institution. In the Irish context, there are 14 loTs, ten of which provide tourism and hospitality courses at some level, ranging from certificate to research-led PhDs. There are seven Irish universities, with only one providing a tourism or hospitality related course (MA in International Tourism) and research-led PhDs within this discipline. Some of the private colleges provide tourism or hospitality related courses up to honours degree level.

In planning the survey, both the research questions and target population were considered. For the most part, the items used in the survey were derived from previous studies (Akama \& Kieti, 2003; Etchner \& Ritchie, 1993). The aim of the survey was to ascertain tourism and hospitality scholarly activity within Irish HE institutions. Once the pilot study was completed and suggested alterations made, 100 surveys were distributed in August 2006 and reminders were issued during the following month (September). The four-part survey comprised 17 questions and classified the respondents by their position and institution.

\section{Research questions}

Yin (2003) reveals that identification of the questions that are most important for a topic and the formulation of these questions involve a lot of preparation. One way is to evaluate the literature on the topic (Cooper, 1984). The design of the research questions requires conceptual organisation, consideration of ideas, connection of the theory that is already known, guidance on cognitive structures for data gathering and presentation of this interpretation to others (Stake, 1995).

A series of open-ended and closed questions on tourism and hospitality education, research and scholarly activity were included in the survey. With open-ended questions, the respondents are allowed to answer in their own words and the researcher may get some unexpected answers. They may also demonstrate the legitimate views of the respondents. Consequently, open-ended questions on tourism and hospitality scholarly activity were included in the survey. An example of an open-ended question included in this survey is: How does your institution view research and/or scholarly activity? Thus, a series of both closed and open-ended questions were included in the survey.

\section{Research analysis}

The surveys were undertaken to elicit ideas and gain insights into a number of issues that arose from the literature. Analysis of the research took place in October 2006. A response rate of 58 per cent was achieved, which was representative of the HE institutions that provide tourism and/or hospitality courses or partake in such research in Ireland. It is worth noting that, of the 58 respondents surveyed, only 12 were employed by the three HE establishments that had an established tourism research centre on site: Dublin Institute of Technology, Galway-Mayo Institute of Technology and University of Limerick. 


\section{Findings}

\section{Research policies and approaches in Irish tourism and hospitality HE institutions}

Research and scholarly activity are becoming increasingly important components of HE, as the results of the survey show. Research is generally a process or activity in which knowledge is tested or developed. Scholarly activity refers to an oral or written presentation that reflects a thorough and critical collection of knowledge; it is of high quality and is a prerequisite in an academic environment increasingly providing degree-level studies. Research is an essential element in Ireland's drive to move economic activity up the value chain and improve competitiveness. This was suggested by several respondents (10). Knowledge-based economies and regions are built on a strong research infrastructure, and the development of a strong research capability within the HE sector supports this. The majority of the respondents (46) maintained that their own HE establishment had a research strategy in place, which indicates that research within Irish HE institutions is seen as a key factor for future success.

\section{Developing a research strategy}

It should be noted that HE institutions have different definitions, depending on departments, number of experiences, personnel involved and funding levels. Again, IoT 7 seemed to place special emphasis on research, which it referred to as fundamental, and applied research, including scholarship, creative work and professional consultancy. One interesting observation is that many (12) of the Irish HE institutions surveyed stated that they did not have an institute-wide definition of research. University 3 stated that research 'is supposed to contribute to the themes chosen by the HE institution as being significant to Ireland's economic progress but this research should be applied'. IoT 7's classification of research was very broad, allowing the incorporation of various types, including empirical research, adding to the breadth of knowledge, 'self-tasked' research, scholarly research, team-based research (in 'clusters'), and other forms of productivity such as creative output.

Of the respondents, 46 ascertained that their HE institutions had a research strategy in place. IoT 1 defined research as 'work that is news and contributes to the institute and industry'. Research was actively encouraged at IOT 3 and a specific research scholarly strategy had been created to highlight this. IoT 4 classified research as 'an important part of academic achievement while it is also exclusive to course design and curriculum development' and loT 5 described it 'very much as academic, following a structured model with less emphasis on applied research and more on journal publication'.

\section{Research-led teaching}

All of the respondents felt that research should be integrated into education. IoT 6 suggested that it had 'a particular duty to support the development of its region in economic, social and cultural terms while research is encouraged in all academic activities'. The majority of the respondents (37) felt that the successful integration of teaching tourism-related courses and the growth in related research could be positively integrated through tourism and hospitality scholarly activities, which any HE institute offering tourism and hospitality courses and engaging in such research should pursue. IOT 7 saw 'scholarly activity as a necessity, a core activity and central to its vision'. It actively promoted research and a particular emphasis was placed on developing relationships with external parties. IOT 7 was also committed to the creation of research-driven learning; this was recognised as a key part of moving forward, particularly given the focus on fourth-level education. It viewed research as part of an integrated framework, incorporating policy and procedures of performance management and evaluation, research support and industry-academic partnership. University 3 classified research as 'vital especially with the need in Ireland for this level of education'. Research was highly regarded within the structure of loT 8. There was an emphasis on scholarly activity and, as a consequence, staff were encouraged to participate. 
In loT 4 'strategic goals were in place to integrate research as a core activity driven by the departments while underpinning teaching in a supportive and resourceful environment'. The IoT's administration function was to support and encourage research, and the institution considered it an essential aspect of pedagogical development for individual lecturers. It also viewed research as important but not well-facilitated owing to heavy timetable loads and inadequate training in research methods for staff. Private college 2 viewed research and/or scholarly activity as 'important in sustaining development as it underpins all teaching and student development. It is also a vital component that enhances the skill set of individuals and the investigation of important themes affecting the industry and college'.

\section{Supporting staff research}

Nearly all of the respondents (50) felt that part of their current role was to support staff in research. In IoT 1, research was 'encouraged, supported and ... viewed positively but this is not reflected in terms of resources allocation, though recently there is more emphasis on teaching'. In University 2, research was viewed very highly. IoT 5 said that 'problems such as time allocation limit such research'. University 3 viewed research as an essential part of academic work within the university. In University 4, there was a major emphasis on research, especially in relation to individual promotion. In IoT 2, research was a 'necessary activity for all staff whether funded or not'. Private college 1 was committed to the promotion of a research culture across all disciplines through its strategic approach, policy provision and implementation plans. Research was regarded as a 'third task in conjunction with other academic activities' in loT 6.

IOT 3 characterised research scholarly activity as 'assisting regional development and the development of the Institute's economic, social and cultural hinterland' and would like to encourage it more but could not owing to budget constraints. There was no time allowance for research. IOT 9 aimed to develop and nurture research capability in niche areas, and external funding continued to be sought to expand research opportunities for both staff and students. In University 1, research was rated as the highest priority among each academic's responsibilities, while in loT 5 research was supported where appropriate. Staff promotions within other HE institutions, such as Universities 1, 2, 4 and IoT 8, were very dependent on research output and increasingly there were no appointments at even junior level without significant publications. There was also a strong need for individual academics to publish in order to get promoted.

Many respondents (44) mentioned that lecturers should be allocated timetabled hours to undertake research in a structured manner, as a full teaching load was highly unproductive for active researchers. Flexible working hours were also needed because they attracted valuable findings and increased profile within industry. In loT 4 there was 'very little time to look at hospitality research due to full lecturing schedules and no time allocation for course management and administration'. IOT 7, for example, only allowed time for postgraduate supervision. Sabbaticals are an option as are research secondments, which some Irish HE institutions offer. In recognition of the strategic importance of research activity, IoT 10, for example, intended to 'rebalance the allocation of resources between teaching and research'. In University 5, staff were 'facilitated in making applications for research grants'. IoT 2 allocated 'a portion of their overall budget to research groups for specific research activities which can support in forthcoming curriculum and course objectives'. IoT 7 encouraged 'research with industry in the hope of attracting funding and increasing the institute profile'. In IOT 1, 'funding, facilities and admin support are supplied and staff are encouraged to publish in academic, scholarly and journalist media'. IOT 8 had an 'internal research fund, facilities, equipment to support research and a staff development fund is also available'. In loT 4 and IOT 9 there was 'general funding available for research', while loT 3 offered 'seed funds but not hours off teaching'.

\section{The successful integration of research with industry}

Many of those surveyed believed that research collaborations between colleges and industry should be encouraged through developing realistic projects in phases where both colleges and industry see short and long-term results/outputs. It was also put forward that the loTs 
should be proactive in gaining additional funding for research and in promoting and encouraging a research agenda. Research can enhance significantly the level of interaction between industry and HE educators, but by identifying the link between both areas, applied comparisons can be beneficial.

\section{Discussion}

As seen in this research, the successful integration of research with industry can be further achieved by showing the value and significance of research for all levels/courses and by highlighting the value-adding capability and research-informed teaching. It might be encouraged by focusing on hospitality and tourism as a first-choice career and developing students' knowledge of career opportunities. This can be achieved through the mobility of staff between industry and academia through sabbaticals and secondments, mentioned previously. As with IoT 7, industry would benefit from best practice in research, while academics would be exposed to industry problems and the market-related issues facing industry, as well as having the opportunity to maximise their research results.

With even more emphasis on and recognition of the importance of the researching academic, IOT 3 suggested that staff should be involved in research activities which are supported and encouraged both internally and externally. Research contributes to the body of knowledge and will influence economic development and innovation regionally and nationally. The successful integration of research with industry can be strengthened by ensuring that sufficient numbers of staff in lecturing positions are researchers themselves and share their research with students and graduates at postgraduate level.

\section{Implementing tourism and hospitality scholarly activity}

Research in tourism should be seen as a multidisciplinary activity which involves business, technology and the arts. The challenge is to develop a model which can motivate transdisciplinary activity. If the Irish HE institutions are to promote scholarly activity, it needs to be done in a manner that is specific to them. The following key points extend the work of Boyer (1990), as highlighted by Roberts (2006), and suggest areas in which Irish HE institutions can demonstrate scholarly activity.

\section{Publication productivity}

The idea that publication productivity should be part of tourism and hospitality scholarly activity was very much supported by the respondents. This depends on how it is measured; and if such productivity is required there must be time allocation for individuals engaged in this activity. It should be noted that published articles should only be recognised if they are worthwhile pieces of academic research, appearing in scholarly, peer-reviewed journals or in books published by reputable academic presses.

\section{The integration of research into teaching}

The interpretation of teaching and researching is complex. Departments of tourism and hospitality should carry out research to meet the needs of the regions, as loTs were formed for this sole purpose. Researchers should incorporate their expertise in their programme delivery. There also needs to be a focus on attracting students from other disciplines to undertake postgraduate research. More critical research could stimulate the intellectual potential of students. It needs to be aligned with existing research activity in other disciplines such as business. It is important that the knowledge generated by research is used in the development and revision of course material. All courses should incorporate some element of research and should be directly aligned with the research activity. The HE institutions in Ireland are relatively small and it is difficult to create a research culture if lecturers teach 18 hours a week and academics are also required to assist in course development and administration. This was highlighted by most of the respondents (51) as a restricting factor in the research being undertaken.

Irish HE institutions can demonstrate research activity by researching up-to-date and useful topics emanating from discussion between industry and academia. Research informs not only teaching but also the industry; teaching cannot ignore research in preparing students for practice. 


\section{Implementation}

Results from the survey implied that each HE institution should determine which areas of activity need to be addressed. This would help them develop a more structured approach than they currently have, as staff would decide which areas of scholarly activity they wished to undertake. Consequently, it is not easy to show a strategic approach. Roberts (2006) concludes that researching as part of a team is almost always more effective than carrying out research alone. It would therefore seem useful to consider having research groups comprising volunteers interested in scholarly activity to undertake work in each of the areas.

\section{Measurement}

Any HE institution's strategic plan may go as far as requiring lecturers to be active in at least one of the above areas for a designated period of time (Roberts, 2006). With reference to the loTs, attempting to show evidence of staff being at least involved in 'research' is problematic owing to the following issues:

- first, as they are teaching institutions, having evolved only since the 1970 s into the $\mathrm{HE}$ sector, student contact hours continue to exceed those of traditional universities. Much of the operation of traditional universities is research-funded; hence, such institutions obviously employ staff specifically to carry out research

- second, along with relatively high student contact hours, staff perform administrative duties while helping to promote staff with a strong understanding of the design, delivery and effect of the curriculum, of quality procedures and the student experience. This means that there is little time for 'research' activities

- third, staff are employed as lecturers, not as researchers. Therefore the methods, procedures and execution of research are not always areas that can be entered into confidently by all members of staff. This remains problematic without a significant change in recruitment, staffing and timetabling, and also if Irish HE institutions continue to use the term 'research' in rather a narrow way as in research-aspublication (Roberts, 2006)

\section{Conclusions and recommendations}

The following conclusions and recommendations could be put forward in light of this research study:

- the development of stand-alone tourism research centres within Irish HE can promote and attract funding for research activities through networking and partnership between the HE institutions, fully-funded tourism research centres and support for further academic research in tourism

- best practice in tourism research internationally and the benchmarking of Irish current practice needs to take pace, as well as a network of Irish tourism research academics

- the number of staff undertaking scholarly activity needs to be increased to ensure that scholarly activity is output promoted, and a framework to guide progress in this respect needs to be adopted

- it is necessary to ensure that those already conducting research of national or international importance are encouraged to climb their way up the publishing ladder

- tourism researchers need to collaborate actively with researchers from other disciplines, which would also assist in addressing the funding crisis

- it may be of interest to investigate why so few lecturers in tourism and hospitality in Ireland are engaging in such research

The main limitation of this research lies with the generalisability of its findings. A main drawback is that it is a case study based on one area. Consequently, it is acknowledged that generalisation of the results secured is speculative (Zikmund, 1997). This method was suitable given the contemporary nature of the situation and the acceptability of the case study one-shot method. Yet, because the primary research focus was on Ireland, the extent to which the findings are transferable to other countries is not clear, and for that reason the results need to be viewed with caution. Additional research, encompassing a larger range of 
O'Connor and Baum (2008) An investigation into the tourism and hospitality scholarly activity currently being undertaken in Irish higher education institutions

case studies, to reveal the tourism and hospitality scholarly activity currently taking place elsewhere, would be advantageous.

\section{References}

Akama, J. S., \& Kieti, D. M. (2003) Measuring tourist satisfaction with Kenya's wildlife safari: a case for Tsavo West National Park. Tourism Management, 24(1), 73-81. doi:10.1016/S02615177(02)00044-4

Beeton, S. (2000). It's a Wrap! What happens after the film crew leaves? An examination of community responses to film-induced tourism. In N. P. Nickerson, N. Moisey and K. L. Andereck (Eds.), Proceedings of the $31^{\text {st }}$ Annual Travel and Tourism Research Association Conference, 1114 June, 2000 (pp. 127-136). Burbank, California.

Boyer, E. L. (1990). Scholarship Reconsidered: Priorities of the Professoriate. Princeton, New Jersey, USA: Carnegie Foundation for the Advancement of Teaching.

Brown, F.E. (1980). Marketing Research: A Structure for Decision Making. Addison Wesley: Reading, Massachusetts, USA.

Cooper, D. R., \& Emory, W. C. (1995). Business Research Methods (5th ed.). Chicago, USA: Irwin.

Cooper, H. M. (1984). The Integrative Research Review. Beverly Hills, California, USA: Sage.

Echtner, C. M., \& Ritchie, B. J. R. (1993). The Measurement of Destination Image: An Empirical Assessment. Journal of travel research, 31(3), 3-13. doi:10.1177/004728759303100402

Elsworth, J. D., Yoon, B. J., \& Bai, B. X. (1999). Analysis of Papers Published in the Hospitality Research Journal: Focus and Trends of Subjects, Research Designs and Statistical Designs. In K. Chon (Ed.), The Practice of Graduate Research in Hospitality and Tourism (pp. 163-175). New York: Haworth Hospitality Press.

Higher Education Authority (2008). Glossary. Retrieved January 14, 2008, from http://www.hea.ie/index.cfm/page/sub/id/519

Government of Ireland (2006). Institutes of Technology Act. Retrieved January 15, 2008, from http://www.irishstatutebook.ie/2006/en/act/pub/0025/index.html

Jennings, G. (2001). Tourism Research. Australia: John Wiley and Sons.

Roberts, A. (2006). The Development of a Tourism and Hospitality Scholarly Activity Model for the Birmingham College of Food, Tourism and Creative Studies. Birmingham College of Food Tourism and Creative Studies.

Stake, R. E. (1995). The Art of Case Study Research. Newbury, Park, California, USA: Sage Publications.

Trochim, W. M. K. (2008). Five Big Words. Retrieved April 14, 2008, from www. socialresearchmethods.net/kb/naturres.php

Virginia Polytechnic Institute and State University (2008). Scholarly Activity Definition. Retrieved April 14, 2008, from http://www.cals.vt.edu/facultystaff/evaluation/scholarlyactivitydefinition.html

Yin, R. K. (2003). Case Study Research: Design and Methods (3rd ed.). California, USA: Thousand Oaks, Sage Publications.

Zikmund, W. G. (1997). Business Research Methods. Orlando, USA: The Dryden Press, Harcourt Brace College Publishers.

\section{Appendix}

\section{Institutions surveyed}

Athlone Institute of Technology

Cork Institute of Technology

Dublin City University

Dublin Institute of Technology.

Dundalk institute of Technology.

Fáilte Ireland

Galway-Mayo Institute of Technology

Griffith College Dublin

Institute of Technology Tralee

Institute of Technology Sligo

Institute of Technology Tallaght

Limerick Institute of Technology

National Centre for Tourism Policy Studies (University of Limerick)

NUI Galway

NUI Maynooth

Shannon College of Hotel Management 
O'Connor and Baum (2008) An investigation into the tourism and hospitality scholarly activity currently being undertaken in Irish higher education institutions

Tourism College Killybegs (Letterkenny Institute of Technology).

Trinity College Dublin

University of Limerick

Waterford Institute of Technology 